\title{
Red light optimized physiological traits and enhanced the growth of ramie (Boehmeria nivea L.)
}

\author{
M. REHMAN*, S. FAHAD ${ }^{* *}$, M.H. SALEEM ${ }^{* * *}$, M. HAFEEZ\#, M.H. UR RAHMAN"\#,\#\#, F. LIU*,+, \\ and G. DENG*,+ \\ School of Agriculture, Yunnan University, 650504 Kunming, China* \\ Department of Agriculture, University of Swabi, Khyber Pakhtunkhwa, Pakistan** \\ College of Plant Science and Technology, Huazhong Agricultural University, 430070 Wuhan, China ${ }^{* * *}$ \\ Department of Microbiology, Zhejiang Academy of Agricultural Sciences, China ${ }^{\#}$ \\ Department of Agronomy, MNS - University of Agriculture, Multan, Pakistan ${ }^{\# \#}$ \\ Institute of Crop Science and Resource Conservation (INRES), Crop Science Group, University Bonn, Germany ${ }^{\# \#}$
}

\begin{abstract}
Light is an important variable affecting the plant growth. In present study, the effects of different color light-emitting diodes (mixed colors, red, blue, and orange light) on plant growth, gas exchange, and oxidative stress were investigated in Boehmeria nivea L., by means of measuring growth, photosynthesis, chlorophyll (Chl) content, reactive oxygen species (ROS), and activity of antioxidant enzymes under controlled conditions. Comparing to the mixed colors light, red light significantly increased shoot and leaf biomass, plant height, number of leaves per plant, and stem diameter by increasing the $\mathrm{Chl}$ content and therefore promoting the highest photosynthetic capacity. This might partially be explained by the decrease of malondialdehyde and proline contents as well as the activities of superoxide dismutase and peroxidase under red light, to keep a better internal environment of the cell. However, blue and orange light decreased plant growth, and increased the activities of antioxidant enzymes which suggest an environmental stress on plants. These results suggest that red light can enhance $B$. nivea growth by activating photosynthesis and reducing ROS accumulation.
\end{abstract}

Additional key words: antioxidant system; gas-exchange parameters; light quality; morphological traits.

\section{Introduction}

Boehmeria nivea L. (ramie) is an ancient perennial plant with a rapid growth, nutritional value, and multifunctional applications in textiles, livestock feed, medicine, and environmental conservation (Rehman et al. 2019). This light-demanding species is widely grown as a bast fiber crop all over the China. It can be used as fresh fodder, or can be artificially dried to produce a leaf meal. Its farming, industry, and trade provide living support to about 5 million people (An et al. 2017). Ramie fiber has a good quality, color, and appearance, which can give strength to textile industry (Rehman et al. 2019). However, it has been reported that stress conditions before harvest can inhibit the growth of $B$. nivea. Thus, it is essential to find out the most advantageous environmental conditions for better growth of $B$. nivea.

Light wavelengths have varying effects on the growth of plants. During photosynthesis in green plants, light energy is captured and used to convert into energy-rich organic compounds (Fukuda et al. 2008). However, quality of light or shifting wavelengths can affect morphology, anatomy, physiology or development and is identified by phytochromes in plants (Haliapas et al. 2008, Kami et al. 2010). For example, red light contributed to higher plant biomass and starch contents, while blue light caused higher contents of $\mathrm{Chl}$ and vitamin $\mathrm{C}$ in Brassica campestris (Li et al. 2012). According to Landi et al. (2020) monochromatic light affects not only plant photosynthetic performance but also the 'quality' of plants by modulating the biosynthesis of photoprotective compounds. In a previous study, Simlat et al. (2016) reported that blue light resulted in an increased germination rate, number of leaves and roots, higher stomatal frequency and pigment contents, as well as antioxidant enzyme activities in Stevia rebaudiana Bertoni. Orange light increased the germination of Bletilla ochracea Schltr. seeds and induced the formation of rhizoids (Godo et al. 2011). Meanwhile, previous literature on different colors of light suggests that plant's response to light stress is species specific

Received 6 February 2020, accepted 4 May 2020.

+Corresponding author; e-mail: denggang1986@ynu.edu.cn (G. Deng), dmzpynu@126.com (F. Liu)

Abbreviations: $\mathrm{BL}$ - blue LED light; $C_{\mathrm{i}}-$ intercellular $\mathrm{CO}_{2}$ concentration; $\mathrm{CK}$ - mixed colors LED light as control (white); DM - dry mass; $E$ - transpiration rate; FM - fresh mass; $g_{\mathrm{s}}$ - stomatal conductance; LED - light-emitting diodes; MDA - malondialdehyde; OL orange LED light; $P_{\mathrm{N}}$ - net photosynthesis; POD - peroxidase; RL - red LED light; ROS - reactive oxygen species; SOD - superoxidase dismutase; SPAD - Soil Plant Analysis Development.

Acknowledgements: This work was supported by Fundamental Research Funds for the Central Universities (2662015PY059), China Agriculture Research System project (CARS-16-E12), and the National Natural Science Foundation of China (31571717). 
(Hogewoning et al. 2010, Cope and Bugbee 2013), mediated by different photoreceptors. For example, cucumbers are known to be more responsive towards light spectral distribution than other greenhouse plants, such as pepper and tomato (Hemming et al. 2008, Trouwborst et al. 2010, Hernández and Kubota 2012). Chen et al. (2014) showed that lettuce plant biomass and stem diameter were lower under monochromatic blue as compared to monochromatic red light.

Stress environment causes generation of reactive oxygen species (ROS), such as superoxide radical $\left(\mathrm{O}_{2}^{-{ }^{-}}\right)$, $\mathrm{H}_{2} \mathrm{O}_{2}$, singlet oxygen $\left({ }^{1} \mathrm{O}_{2}\right)$, and hydroxyl radicals $(\mathrm{OH})$ (Fahad and Bano 2012, Fahad et al. 2013, 2014, 2015a,b,c; 2016a,b,c,d; 2017, 2018; Saud et al. 2014, 2016, 2017a,b; Liu et al. 2015, Ma et al. 2019, Turan 2019, 2020). In order to prevent oxidative stress, the plants respond to ROS by activating an antioxidant defense system in their cells (Kurutas 2016). Deng et al. (2012) reported that plants under stressful environment can augment lipid peroxidation as malondialdehyde (MDA), in their tissues, indicating the occurrence of oxidative stress. Proline accumulation is also an adaptive behavior in plants against stressful conditions. Proline is a signal molecule activating physiological and molecular responses (Szabados and Savouré 2010). Accumulation of proline due to increased synthesis and decreased catabolism under stress conditions has been documented in several plants (Mani et al. 2002).

Plants have an efficient antioxidant defense system including superoxide dismutase (SOD), peroxidase (POD), and catalase (CAT) which is involved in protecting plant cells by scavenging of ROS (Lall et al. 1999, Procházková et al. 2001, Alici and Arabaci 2016). However, antioxidant enzymes activity in plants under different light spectra is more complex. For example, ascorbate peroxidase and SOD were notably influenced by light intensity in different ways (Bayat et al. 2018). Manivannan et al. (2015) reported that blue light improves antioxidant enzyme activities in Rehmannia glutinosa cultured in vitro. Similar results were reported for tomato leaves (Kim et al. 2013). Conversely, the antioxidant activity of pea and Dendrobium officinale seedlings was improved under red light $(\mathrm{Wu}$ et al. 2007, Wang et al. 2017). These findings suggest that light spectrum distribution evokes diverse morphological, photosynthetic, and antioxidative responses in different plant species with contrasting results. Therefore, it is requisite to find out appropriate light quality for plants, grown under artificial conditions.

Therefore, the main objective of present study was to investigate the effects of different light quality on growth, Chl content, leaf gas-exchange characteristics, and antioxidant capacity of $B$. nivea tissue, to explore the relationship between growth, photosynthesis, and antioxidant capacity, and to screen out the most favorable light spectrum for standardized production of $B$. nivea. This study would provide reference for the regulation of light quality environment of $B$. nivea and other crop plants.

\section{Materials and methods}

Plant material and growth conditions: The pot experiment was carried out under controlled conditions in a glasshouse, at Huazhong Agricultural University Wuhan, China in 2018. Physicochemical properties of soil were: $\mathrm{pH} 6.0, \mathrm{EC}$ of $2.0 \mathrm{dS} \mathrm{cm}{ }^{-1}, 22.2 \mathrm{~g}$ (organic matter) $\mathrm{kg}^{-1}$, $23.1 \mathrm{mg}$ (exchangeable potassium) $\mathrm{kg}^{-1}, 19.9 \mathrm{~g}$ (total nitrogen) $\mathrm{kg}^{-1}, 0.25 \mathrm{~g}$ (total phosphorous) $\mathrm{kg}^{-1}$. Uniform rhizome segments of $15 \mathrm{~cm}$ were taken from roots of $B$. nivea, cultivar 'Zhongsizhu 1', and planted in pots of $30-\mathrm{cm}$ length and 40-cm width. Each pot contained $14.0 \mathrm{~kg}$ of soil. After planting, pots were placed in natural light for seven days, and then moved under color LEDs. Treatments of different light quality included mixed colors light as white light (CK), red light (RL), blue light (BL), and orange light (OL) (Fig. 1). LEDs light wavelengths are given in Fig. 2. Each treatment was set in a completely randomized design (CRD). Fertilizer was applied at a recommended dose. Weeding and irrigation was done with metal-free water when needed. Pots were placed within different color LED cabins covered with porous black sheet under a glasshouse. Analytical grade chemicals obtained from Sinopharm Chemical Reagent Co., Ltd. (China) were used in this study.

Sampling and data collection: During the rapid growth period of crop, $5^{\text {th }}$ fully expanded and healthy leaf from top (functional leaf) for each treatment was picked at 09:00-10:30 h, cleaned, and immediately frozen in liquid nitrogen before being stored in $-80^{\circ} \mathrm{C}$ until further analysis. Before harvesting, three plants from each treatment were sampled and then plants were carefully harvested after $30 \mathrm{~d}$ from shifting under light quality treatments, by cutting the stems at a height of $5 \mathrm{~cm}$ from the soil surface. Total number of leaves and stems per plant was counted and plant height $[\mathrm{cm}]$ was measured by meter scale from soil surface to the plant tip. Stem diameter $[\mathrm{mm}]$ at a height of $15 \mathrm{~cm}$ from root neck was measured using a digital vernier caliper (ST22302, SG Tools, Hangzhou, China). Fresh shoot biomass and fresh leaf biomass were determined by weighing aboveground plant parts and leaves, respectively. These plant parts were then oven dried at $70^{\circ} \mathrm{C}$ for $72 \mathrm{~h}$ until constant mass and then weighed to get their dry mass.

Chl content and gas exchange: The Chl content of the fully expanded and healthy leaf at the stage of rapid plant growth was measured for each treatment during 09:00 10:30 h using a Soil Plant Analysis Development meter SPAD-502 plus (Konica Minolta, Inc., Japan). Nine leaves were selected from each treatment for the measurement of gas-exchange attributes, such as net photosynthesis $\left(P_{\mathrm{N}}\right)$, transpiration rate $(E)$, stomatal conductance $\left(g_{\mathrm{s}}\right)$, and intercellular $\mathrm{CO}_{2}$ concentration $\left(C_{\mathrm{i}}\right)$, from 9:00-11:00 h using a portable photosynthesis system $\mathrm{Li}-6400$ ( $\mathrm{Li}-\mathrm{COR}$, Lincoln, NE, USA).

Lipid peroxidation and proline content: Lipid peroxidation in ramie leaves was measured by thiobarbituric acid (TBA) test, which determines the content of malondialdehyde (MDA), an end product of lipid peroxidation (Heath and Packer 1968). Leaf material (0.5 g) was homogenized in $5 \mathrm{ml}$ of $0.1 \%$ trichloroacetic acid (TCA). The homogenate was centrifuged for $5 \mathrm{~min}$ at $10,000 \times \mathrm{g}$ and $1 \mathrm{~mL}$ of supernatant was added to $4 \mathrm{~mL}$ of $20 \%$ TCA 

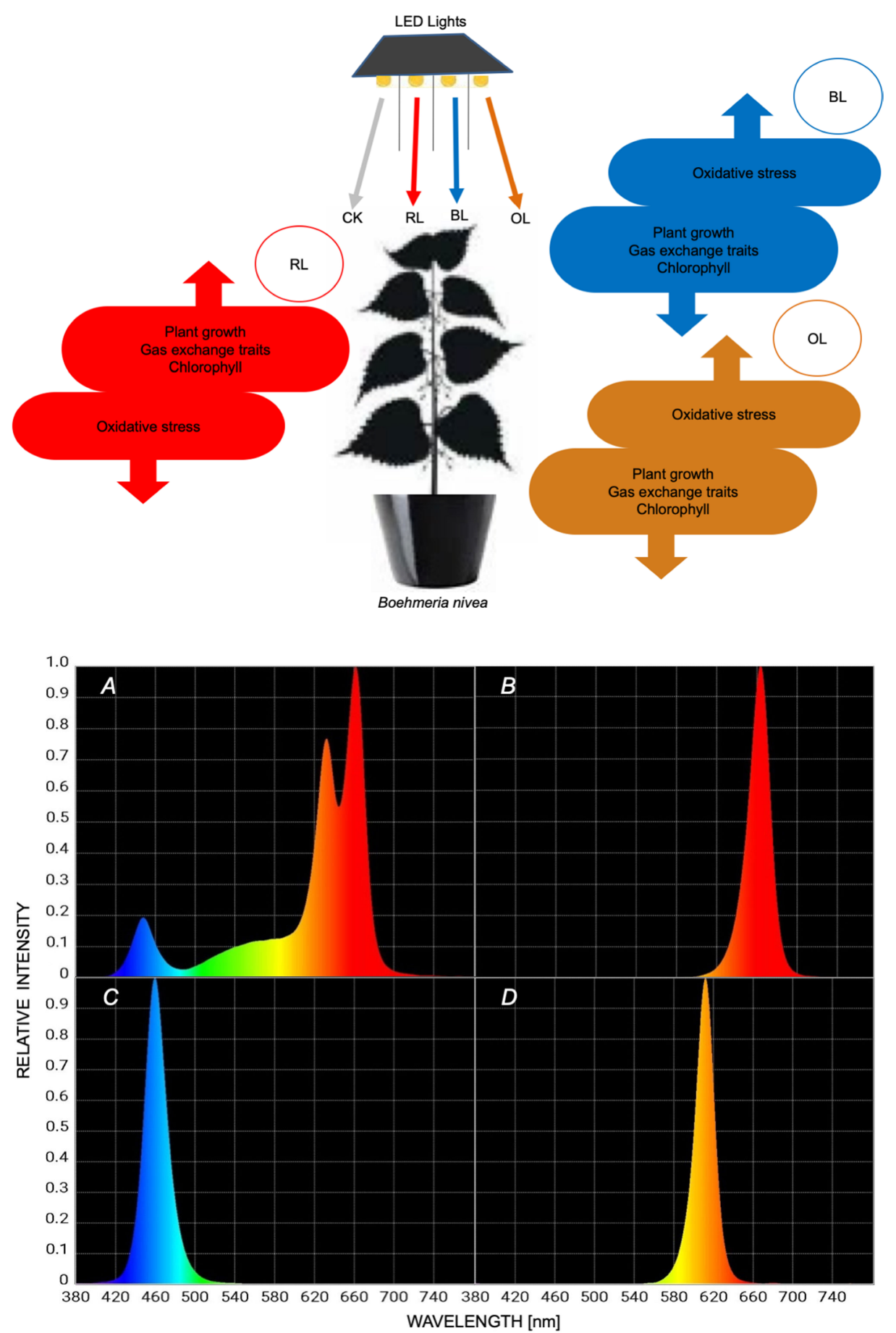

Fig. 1. A schematic diagram representing different color light treatments and their effects on Boehmeria nivea $\mathrm{L}$. BL - blue LED light; CK - mixed colors LED light as control (white); OL - orange LED light; RL - red LED light.
Fig. 2. Wavelengths and relative intensity of CK (mixed color LED light), RL (red LED light), BL (blue LED light), and OL (orange LED light). containing $0.025 \mathrm{~mL}$ of $0.5 \%$ TBA. The mixture was incubated at $95^{\circ} \mathrm{C}$ in a hot water bath for half an hour and placed in an iced-water bath to stop the reaction. Later the material was centrifuged for $15 \mathrm{~min}$ at $10,000 \times \mathrm{g}$ and the absorbance of the supernatant was read at 532 and $600 \mathrm{~nm}$ using a microplate absorbance spectrophotometer (xMark ${ }^{T M}$, Bio-Rad, United States). Read for nonspecific absorption at $600 \mathrm{~nm}$ was subtracted. The amount of MDA was calculated from the extinction coefficient $155 \mathrm{mM} \mathrm{cm}^{-1}$.

Leaf proline content was measured according to the method of Bates et al. (1973). The leaf material was homogenized in sulphosalicylic acid. Then the homogenate was filtered by filter paper (Whatman's no. 1). The obtained filtrate was boiled for 60 min after adding acetic acid and acid ninhydrin, then absorbance was taken at $520 \mathrm{~nm}$ using spectrophotometer (xMark ${ }^{T M}$, Bio-Rad, United States) and expressed in $\mu \mathrm{g} \mathrm{g}^{-1}(\mathrm{FM})$.

Antioxidant enzymes activity: Superoxide dismutase (SOD, EC 1.15.1.1) and peroxidase (POD, EC 1.11.1.7.) were determined in crude extracts extracted by crushing 
$0.5 \mathrm{~g}$ of fresh leaves using liquid nitrogen followed by homogenization in $5 \mathrm{ml}$ of $50 \mathrm{mM}$ sodium phosphate buffer $\mathrm{pH} 7.0$, containing $0.5 \mathrm{~m}$ methylene-diaminetetraacetic acid and $0.15 \mathrm{M} \mathrm{NaCl}$. Then the homogenate was centrifuged for $10 \mathrm{~min}$ at $4^{\circ} \mathrm{C}$ and $12,000 \times g$. The supernatants were used for assay of SOD and POD.

Activity of SOD enzyme was determined in a reaction mixture consisting of $50 \mathrm{mM}$ sodium phosphate buffer of $\mathrm{pH}$ 7.0, $10 \mathrm{mM}$ methionine, $1.17 \mathrm{mM}$ riboflavin, $56 \mathrm{mM}$ nitroblue tetrazolium (NBT), and $100 \mu$ of enzyme extract. The solution absorbance was tested by measuring its capacity of inhibiting the photochemical reduction of NBT at $560 \mathrm{~nm}$ using microplate absorbance spectrophotometer (xMark $^{T M}$, Bio-Rad, United States). One unit of SOD was defined as the enzyme activity that reduced the photoreduction of nitroblue tetrazolium (NBT) to blue formazan by $50 \%$ (Chen and Pan 1996). SOD activity was expressed as enzyme $\mathrm{U} \mathrm{g}^{-1}(\mathrm{FM})$.

POD activity was determined following the method of Sakharov and Aridilla (1999) by measuring the increase in absorbance at $470 \mathrm{~nm}$ using microplate absorbance spectrophotometer ( $x$ Mark ${ }^{T M}$, Bio-Rad, United States). The mixture consisted of $2.8 \mathrm{~mL}$ of guaiacol (3\%), $0.1 \mathrm{~mL}$ of $\mathrm{H}_{2} \mathrm{O}_{2}(2 \%)$, and $0.1 \mathrm{~mL}$ of enzyme extract. One unit of POD activity is the increase in absorbance of 1.0 per min. The POD activity was expressed as enzyme $\mathrm{U} \mathrm{g}^{-1}(\mathrm{FM})$.

Statistical analysis: The data were subjected to one-way analysis of variance (ANOVA), followed by Tukey's HSD (Honestly significant difference) test to avoid a type I error, using Statistix 8.1 (Analytical Software, Tallahassee, United States). Testing showed that all data were approximately normally distributed. Statistical variations of data were represented as standard deviation and $p \leq 0.05$ was used to denote statistical significance. GraphPad Prism 6 software and $R$ studio were used for the graphical presentation.

\section{Results}

Plant growth: Shoot fresh mass, leaf fresh mass, shoot dry mass, and leaf dry mass, plant height, number of leaves, and number of stems per plant were greatest for the plants grown under RL, and minimum values for above parameters were observed under OL (Table 1). Shoot and leaf fresh mass decreased by 33.6 and $27.5 \%$ under BL, by 61.9 and $46.4 \%$ under OL, and increased by 10.1 and $14.3 \%$ under RL, respectively, compared with the plants under control $(\mathrm{CK})$. In the same way, shoot dry mass and leaf dry mass decreased by 24.9 and $27.1 \%$ under BL, by 43.8 and $34.4 \%$ under OL, but increased by 12.6 and $8.6 \%$ under RL, respectively, compared with CK. Plant height increased by $27.2 \%$ under RL, which was statistically similar with plant height under BL, whereas OL caused a decrease of $45.1 \%$ in plant height, compared with the CK (Table 2). Number of leaves per plant also decreased by $18.8 \%$ under OL, but increased by $6.9 \%$ under RL, compared with CK (Table 2).

Chl content and gas-exchange traits: A change in SPAD (Chl) was evaluated in $B$. nivea leaves under different color LED lights (Fig. 3). RL enhanced by $10.3 \%$ the Chl contents, however, Chl contents were reduced by 12.0 and $22.9 \%$ under BL and OL, respectively, compared with CK. RL improved photosynthesis in $B$. nivea as indicated by significantly higher values for $P_{\mathrm{N}}, E, g_{\mathrm{s}}$, and $C_{\mathrm{i}}$. However, $\mathrm{BL}$ and OL showed decreased $P_{\mathrm{N}}, E, g_{\mathrm{s}}$, and $C_{\mathrm{i}}$ compared with CK (Fig. 4).

Table 1. Changes in fresh and dry mass of Boehmeria nivea grown under varying colors of light emitting diodes. Values are means $\pm \mathrm{SD}$ $(n=3)$. Different letters within a column indicate significant difference between the treatments $(p \leq 0.05)$. CK - mixed color LED light; $\mathrm{RL}$ - red LED light; BL - blue LED light, OL - orange LED light.

\begin{tabular}{lllll}
\hline Treatment & $\begin{array}{l}\text { Shoot fresh mass } \\
\text { [g per plant] }\end{array}$ & $\begin{array}{l}\text { Leaf fresh mass } \\
\text { [g per plant] }\end{array}$ & $\begin{array}{l}\text { Shoot dry mass } \\
\text { [g per plant] }\end{array}$ & $\begin{array}{l}\text { Leaf dry mass } \\
\text { [g per plant] }\end{array}$ \\
\hline CK & $64.58 \pm 3.03^{\mathrm{b}}$ & $29.51 \pm 0.95^{\mathrm{b}}$ & $12.91 \pm 0.32^{\mathrm{b}}$ & $7.01 \pm 0.23^{\mathrm{b}}$ \\
RL & $71.09 \pm 2.31^{\mathrm{a}}$ & $33.73 \pm 1.70^{\mathrm{a}}$ & $14.53 \pm 0.59^{\mathrm{a}}$ & $7.61 \pm 0.26^{\mathrm{a}}$ \\
BL & $42.91 \pm 2.14^{\mathrm{c}}$ & $21.39 \pm 1.07^{\mathrm{c}}$ & $9.70 \pm 0.66^{\mathrm{c}}$ & $5.11 \pm 0.06^{\mathrm{c}}$ \\
OL & $24.60 \pm 0.66^{\mathrm{d}}$ & $15.81 \pm 0.64^{\mathrm{d}}$ & $7.25 \pm 0.16^{\mathrm{d}}$ & $4.60 \pm 0.14^{\mathrm{d}}$ \\
\hline
\end{tabular}

Table 2. Changes in morphological traits of Boehmeria nivea grown under varying colors of light emitting diodes. Values are means $\pm \mathrm{SD}$ $(n=3)$. Different letters within a column indicate significant difference between the treatments $(p \leq 0.05)$. CK - mixed color LED light; $\mathrm{RL}$ - red LED light; BL - blue LED light, OL - orange LED light.

\begin{tabular}{lllll}
\hline Treatment & $\begin{array}{l}\text { Plant height } \\
{[\mathrm{cm}]}\end{array}$ & $\begin{array}{l}\text { Number of leaves } \\
\text { per plant }\end{array}$ & $\begin{array}{l}\text { Number of stems } \\
\text { per plant }\end{array}$ & $\begin{array}{l}\text { Stem diameter } \\
{[\mathrm{mm}]}\end{array}$ \\
\hline $\mathrm{CK}$ & $52.13 \pm 3.36^{\mathrm{b}}$ & $33.67 \pm 1.15^{\mathrm{b}}$ & $2.67 \pm 0.58^{\mathrm{ab}}$ & $6.19 \pm 0.31^{\mathrm{a}}$ \\
$\mathrm{RL}$ & $66.30 \pm 3.40^{\mathrm{a}}$ & $36.00 \pm 1.00^{\mathrm{a}}$ & $3.33 \pm 0.58^{\mathrm{a}}$ & $6.68 \pm 0.23^{\mathrm{a}}$ \\
$\mathrm{BL}$ & $60.67 \pm 3.79^{\mathrm{a}}$ & $31.33 \pm 0.58^{\mathrm{c}}$ & $2.67 \pm 0.58^{\mathrm{ab}}$ & $5.40 \pm 0.28^{\mathrm{b}}$ \\
OL & $28.63 \pm 2.18^{\mathrm{c}}$ & $27.33 \pm 0.58^{\mathrm{d}}$ & $2.00 \pm 1.00^{\mathrm{b}}$ & $3.71 \pm 0.18^{\mathrm{c}}$ \\
\hline
\end{tabular}


Lipid peroxidation, proline content, and antioxidant enzymes: BL and OL resulted in severe lipid peroxidation in $B$. nivea, compared with CK (Fig. 5). MDA and proline contents were reduced by 12.5 and $12.6 \%$ under RL; but increased by 27.7 and $21.4 \%$ under BL, and by 47.3 and $39.4 \%$ under OL, compared with CK (Fig. 5A,B). The activities of antioxidant enzymes SOD and POD were also affected by differential light quality. SOD activity increased by $14.1 \%$ under OL, but decreased by $8.9 \%$ under RL;

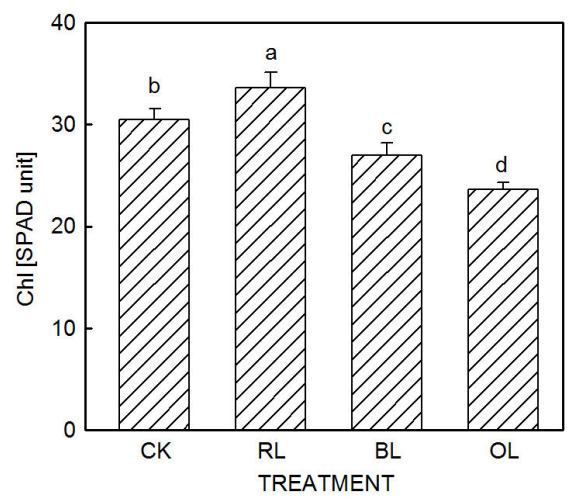

Fig. 3. Effects of differential light quality on SPAD (Soil Plant Analysis Development) value of Boehmeria nivea grown under different color light emitting diodes. CK, RL, BL, and OL designated as mixed color LED light, red LED light, blue LED light, and orange LED light, respectively. Bars indicated the mean $\pm \mathrm{SD}(n=3)$. Different letters on bars indicated significant difference between treatments at $p \leq 0.05$. however, there was no difference in SOD activity under BL, compared with CK (Fig. 5C). POD activity increased by 21.5 and $47.7 \%$ under BL and OL respectively, but was reduced by $35.1 \%$ under RL, compared with CK (Fig. 5D).

Correlation analysis: Correlation between different morphological traits and gas-exchange attributes of $B$. nivea grown under differential light quality is shown in Fig. 6. According to this correlation, fresh and dry shoot and leaf biomass, plant height, and number of leaves per plant were positively correlated with $\mathrm{Chl}$ content, $P_{\mathrm{N}}, E$, and $g_{\mathrm{s}}$ (Fig. 6A). However, these studied growth attributes were negatively correlated with MDA, and proline contents as well as SOD and POD activity in $B$. nivea plants (Fig. 6B). This correlation reflected a close link between studied traits of $B$. nivea.

\section{Discussion}

Light is not only a source of energy, but also an essential signal for plant growth and development (Chory and Li 1997, Kim et al. 2002). Plants require light for whole life span from germination to production of seeds. However, different wavelengths of light have diverse effects on the growth of plants (Fukuda et al. 2008). Several processes in plants, for example, germination, flowering, photosynthesis, biomass accumulation, and stomatal regulation can be controlled and optimized by adjusting light wavelengths (Taylor and Assmann 2001, Taiz and Zeiger 2002, Kim et al. 2004, Pinho 2008, Yeh and Chung 2009, Vänninen et al. 2010, Liu et al. 2016).

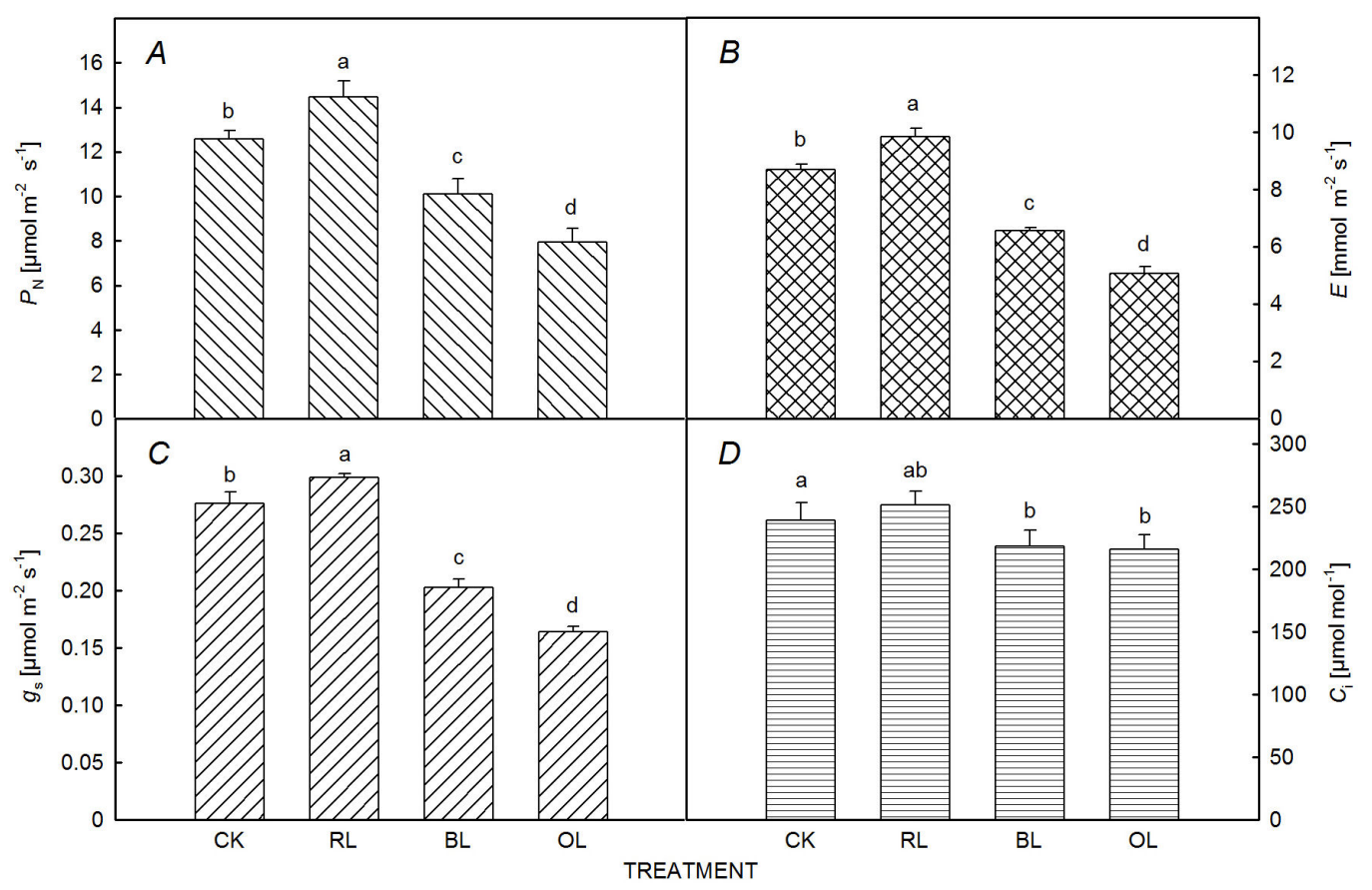

Fig. 4. Effects of differential light quality on net photosynthesis $\left(P_{\mathrm{N}}\right)$, transpiration rate $(E)$, stomatal conductance $\left(g_{\mathrm{s}}\right)$, and intercellular $\mathrm{CO}_{2}$ concentration $\left(C_{\mathrm{i}}\right)$ in Boehmeria nivea grown under different color light emitting diodes. CK, RL, BL, and OL designated as mixed color LED light, red LED light, blue LED light, and orange LED light, respectively. Bars indicated the mean $\pm \mathrm{SD}(n=3)$. Different letters on bars indicated significant difference between treatments at $p \leq 0.05$. 


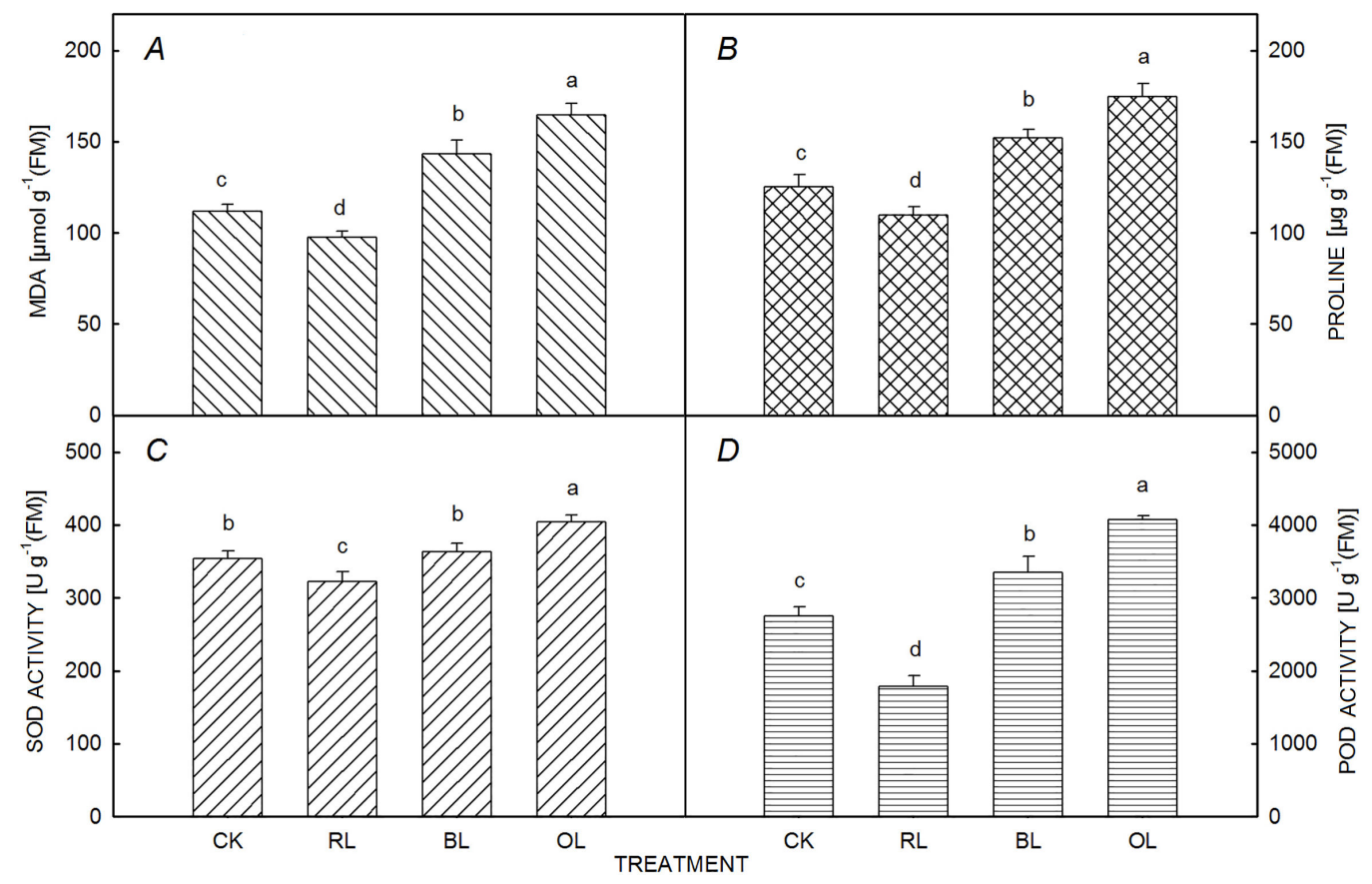

Fig. 5. Effects of differential light quality on malondialdehyde (MDA) content (A), proline content (B), superoxide dismutase (SOD) activity $(C)$, and peroxidase (POD) activity $(D)$ in the leaves of Boehmeria nivea grown under different color light emitting diodes. CK, $\mathrm{RL}, \mathrm{BL}$, and OL designated as mixed color LED light, red LED light, blue LED light, and orange LED light, respectively. Bars indicated the mean $\pm \mathrm{SD}(n=3)$. Different letters on bars indicated significant difference between treatments at $p \leq 0.05$.
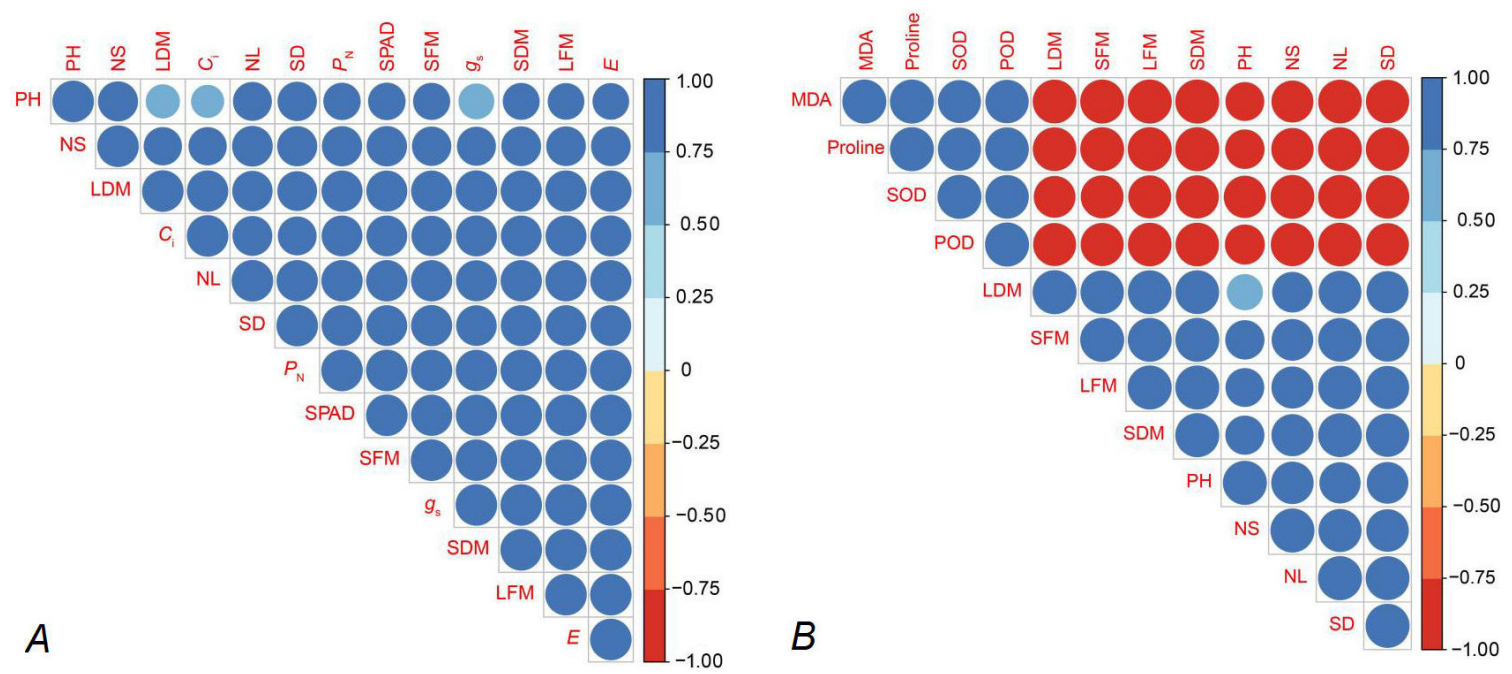

Fig. 6. Correlation of morphological traits with gas-exchange attributes and chlorophyll content $(A)$; correlation of morphological traits and antioxidant system in Boehmeria nivea $(B)$. SFM - shoot fresh mass; LFM - leaf fresh mass; SDM - shoot dry mass; LDM - leaf dry mass; PH - plant height; $\mathrm{NL}$ - number of leaves per plant; NS - number of stems per plant; SD - stem diameter; $P_{\mathrm{N}}$ - net photosynthesis; $E$ - transpiration rate; $g_{\mathrm{s}}$ - stomatal conductance; $C_{\mathrm{i}}$ - intercellular $\mathrm{CO}_{2}$ concentration; MDA - malondialdehyde; Pro - proline; SOD superoxide dismutase; POD - peroxidase.

Frequently used lights for in vitro plant culture, such as fluorescent lamps, high-pressure sodium lamps, metal halide lamps, and incandescent lamps, are of poor light quality with unnecessary wavelengths for improving plant growth. In addition, these light sources require high electrical energy and generate heat in closed chambers
(Kim et al. 2004, Dutta Gupta and Jatothu 2013). However, light emitting diode (LED) is an environment friendly technology for in vitro plant culture with more advantages over traditional light sources (Mitchell et al. 2012). Thus, LEDs appear to be a suitable strategy for improving lightuse efficiency for higher plant growth. In present study, 
we made an effort to investigate the effects of light quality using varying color LEDs (mixed color, red, blue, and orange light) on growth, Chl content, gas exchange, and oxidative stress in $B$. nivea, in order to determine the optimal light spectra for maximal plant growth. Light spectral distribution also has an effect on plant shape, development and flowering (Singh et al. 2015). In present study, BL and OL reduced the plant growth in terms of plant height, plant biomasses, number of leaves per plant, and number of stems per plant as well as stem diameter, however, RL appeared to increase plant growth as shown by higher shoot and leaf biomass, plant height, and number of leaves per plant, compared with control (Tables 1, 2). In our previous study, we observed that RL increased plant height, biomass, photosynthetic pigments, while reduced ROS production in the cell/tissues of Corchorus capsularis plants (Saleem et al. 2019). Similar findings were reported by Dong et al. (2014) in Triticum aestivum L.; the red light thickened the stem and increased the overall ground biomass of plants. Kurepin et al. (2007) reported that red light, mediated by phytochrome, is involved in leaf morphogenesis, photosynthetic apparatus development, and accumulation of carbohydrates. According to Gautam et al. (2015), a reduced quantity of red light results in delay or prevention of flowering, blue and orange lights induced stress which decreased plant growth and biomass; however, red light might increase plant biomass ( $\mathrm{Li}$ and Kubota 2009).

In present study, the increase in $B$. nivea biomass grown under RL might be associated with the increased rate of photosynthesis. RL increased the gas exchange in terms of $P_{\mathrm{N}}, E, g_{\mathrm{s}}$, and $C_{\mathrm{i}}$ (Fig. 4), signifying an increase in the photosynthesis in $B$. nivea plants under RL. Similar results have previously been observed by Shimizu et al. (2011) who reported an increase in photosynthetic pigments and carotenoid contents in lettuce under red light, compared with the plants grown under control conditions. This may clarify that red light was more effective than blue light for Chl synthesis (Eskins and McCarthy 1987). In a previous study, Yanagi et al. (1996) compared the rate of photosynthesis in strawberry (Fragaria $\times$ ananassa L.) leaves under red and blue lights and found higher quantum efficiencies under red light. The role of red-LED light to drive photosynthesis has been widely accepted due to that (1) red wavelengths $(600-700 \mathrm{~nm})$ are efficiently absorbed by photosynthetic pigments and (2) early LEDs were red close to an absorption peak of Chl (Sager and McFarlane 1997). Chloroplast is an organelle that conducts photosynthesis, where the photosynthetic pigment chlorophyll captures the energy from sunlight, converts it, and stores it in the energy-storage molecules (Kirchhoff 2019). However, chloroplast ultrastructure, number of thylakoids and thylakoid area is strongly affected by light exposure (Allen et al. 2011, Chen et al. 2018). The present study showed increased plant height under RL and BL, compared with control. Nanya et al. (2012) studied the effects of red, blue, and combination of red and blue LED lights on morphology of tomato seedlings and found that stem height depended on quantity of blue light. Whereas, according to Hernández and Kubota (2016), blue radiation reduced the length of stem in cucumber, but improved plant extension growth; thus, the response is species specific.

Abiotic stress can promote ROS production; however, plants possess a well-organized protective system to detoxify the ROS (Sharma et al. 2012, Das and Roychoudhury 2014). In current study, plants under BL and OL maintained higher production of MDA and proline, indicating oxidative damage to lipid membranes (Fig. 5), while RL facilitated a reduction of oxidative stress in $B$. nivea. In a recent study, Adil et al. (2019) also reported that red light treatment was most favorable for high biomass accumulation and antioxidant activity in calli of Withania somnifera L. It has been established that LED light wavelengths can enhance not only the antioxidants contents but also the activities of antioxidative enzymes. $B$. nivea plants grown under BL and OL showed the higher activity of antioxidant enzymes, SOD and POD, whereas RL reduced SOD and POD activities, compared with control (Fig. 5). Simlat et al. (2016) reported that the POD activity was enhanced by blue LED light in Stevia rebaudiana Bertoni, whilst red LED light exerted an opposite effect. These results are in agreement with our research. Kim et al. (2013) also reported that higher accumulation of proline in tomato leaves was observed under blue LED, however, the lower content of proline was observed under red LED. Similarly, ROS scavenging enzyme activities also increased under blue LED. This variable antioxidant response might be associated with changes in gene expression and protein function in different plant tissues. Thus ROS-scavenging enzymes, i.e., SOD and POD performance in $B$. nivea serves as an approach to reinforce cell protection system and to reduce ROS production due to light stress.

Conclusion: Our results demonstrated that red LED promoted $B$. nivea growth by improving leaf gas exchange and chlorophyll content, and by reducing ROS accumulation, while blue LED and orange LED both reduced $B$. nivea growth and photosynthesis with raised contents of MDA and proline contents, which may damage membranes in organelles. Furthermore, these results showed that light quality was linked to measured morphological and physiological parameters in $B$. nivea. These results depicted that red light can be successfully implemented for production of $B$. nivea. Furthermore, our study provides a theoretical base for consistent cultivation of $B$. nivea on commercial level for getting quality products.

\section{References}

Adil M., Haider Abbasi B., Ul Haq I.: Red light controlled callus morphogenetic patterns and secondary metabolites production in Withania somnifera L. - Biotechnol. Rep. 24: e00380, 2019.

Alici E.H., Arabaci G.: Determination of SOD, POD, PPO and CAT enzyme activities in Rumex obtusifolius L. - Annu. Res. Rev. Biol. 11: 1-7, 2016.

Allen J.F., Santabarbara S., Allen C.A., Puthiyaveetil S.: Discrete redox signaling pathways regulate photosynthetic lightharvesting and chloroplast gene transcription. - PLoS ONE 6: e26372, 2011.

An X., Zhang J., Liao Y. et al.: Senescence is delayed when 
ramie (Boehmeria nivea L.) is transformed with the isopentyl transferase (ipt) gene under control of the SAG12 promoter. FEBS Open Bio. 7: 636-644, 2017.

Bates L.S., Waldren R.P., Teare I.D.: Rapid determination of free proline for water-stress studies. - Plant Soil 39: 205-207, 1973.

Bayat L., Arab M., Aliniaeifard S. et al.: Effects of growth under different light spectra on the subsequent high light tolerance in rose plants. - AoB Plants 10: ply052, 2018.

Chen C.N., Pan S.M.: Assay of superoxide dismutase activity by combining electrophoresis and densitometry. - Bot. Bull. Acad. Sin. 37: 107-111, 1996.

Chen X.L., Guo W.Z., Xue X.Z. et al.: Growth and quality responses of 'Green Oak Leaf' lettuce as affected by monochromic or mixed radiation provided by fluorescent lamp (FL) and light-emitting diode (LED). - Sci. Hortic.Amsterdam 172: 168-175, 2014.

Chen Y., Zhou B., Li J. et al.: Formation and change of chloroplastlocated plant metabolites in response to light conditions. - Int. J. Mol. Sci. 19: 654, 2018.

Chory J., Li J.: Gibberellins, brassinosteroids and light-regulated development. - Plant Cell Environ. 20: 801-806, 1997.

Cope K.R., Bugbee B.: Spectral effects of three types of white light-emitting diodes on plant growth and development: absolute versus relative amounts of blue light. - HortScience 48: 504-509, 2013.

Das K., Roychoudhury A.: Reactive oxygen species (ROS) and response of antioxidants as ROS-scavengers during environmental stress in plants. - Front. Env. Sci. 2: 53, 2014.

Deng Y., Shao Q.S., Li C.C. et al.: Differential responses of double petal and multi petal jasmine to shading: II. Morphology, anatomy and physiology. - Sci. Hortic.-Amsterdam 144: 19$28,2012$.

Dong C., Fu Y., Liu G., Liu H.: Growth, photosynthetic characteristics, antioxidant capacity and biomass yield and quality of wheat (Triticum aestivum L.) exposed to LED light sources with different spectra combinations. - J. Agron. Crop Sci. 200: 219-230, 2014.

Dutta Gupta S., Jatothu B.: Fundamentals and applications of light-emitting diodes (LEDs) in in vitro plant growth and morphogenesis. - Plant Biotechnol. Rep. 7: 211-220, 2013.

Eskins K., McCarthy S.A.: Blue, red and blue plus red light control of chloroplast pigment and pigment-proteins in corn mesophyll cells: Irradiance level-quality interaction. Physiol. Plantarum 71: 100-104, 1987.

Fahad S., Bajwa A.A., Nazir U. et al.: Crop production under drought and heat stress: Plant responses and management options. - Front. Plant Sci. 8: 1147, 2017.

Fahad S., Bano A.: Effect of salicylic acid on physiological and biochemical characterization of maize grown in saline area. Pak. J. Bot. 44: 1433-1438, 2012.

Fahad S., Chen Y., Saud S. et al.: Ultraviolet radiation effect on photosynthetic pigments, biochemical attributes, antioxidant enzyme activity and hormonal contents of wheat. - J. Food Agric. Environ. 11: 1635-1641, 2013.

Fahad S., Hussain S., Bano A. et al:: Potential role of phytohormones and plant growth-promoting rhizobacteria in abiotic stresses: consequences for changing environment. Environ. Sci. Pollut. R. 22: 4907-4921, 2015c.

Fahad S., Hussain S., Matloob A. et al.: Phytohormones and plant responses to salinity stress: a review. - Plant Growth Regul. 75: 391-404, 2014.

Fahad S., Hussain S., Saud S. et al.: A biochar application protects rice pollen from high-temperature stress. - Plant Physiol. Bioch. 96: 281-287, 2015a.

Fahad S., Hussain S., Saud S. et al.: Responses of rapid viscoanalyzer profile and other rice grain qualities to exogenously applied plant growth regulators under high day and high night temperatures. - PLoS ONE 11: e0159590, 2016a.

Fahad S., Hussain S., Saud S. et al.: Exogenously applied plant growth regulators affect heat-stressed rice pollens. - J. Agron. Crop Sci. 202: 139-150, 2016 b.

Fahad S., Hussain S., Saud S. et al.: Exogenously applied plant growth regulators enhance the morphophysiological growth and yield of rice under high temperature. - Front. Plant Sci. 7: $1250,2016 \mathrm{c}$.

Fahad S., Hussain S., Saud S. et al.: A combined application of biochar and phosphorus alleviates heat-induced adversities on physiological, agronomical and quality attributes of rice. - Plant Physiol. Bioch. 103: 191-198, 2016d.

Fahad S., Ihsan M.Z., Khaliq A. et al.: Consequences of high temperature under changing climate optima for rice pollen characteristics - concepts and perspectives. - Arch. Agron. Soil Sci. 64: 1473-1488, 2018.

Fahad S., Nie L., Chen Y. et al.: Crop plant hormones and environmental stress. - Sustain. Agr. Rev. 15: 371-400, $2015 \mathrm{~b}$.

Fukuda N., Fujita M., Ohta Y. et al.: Directional blue light irradiation triggers epidermal cell elongation of abaxial side resulting in inhibition of leaf epinasty in geranium under red light condition. - Sci. Hortic.-Amsterdam 115: 176-182, 2008 .

Gautam P., Terfa M.T., Olsen J.E., Torre S.: Red and blue light effects on morphology and flowering of Petunia $\times$ hybrida. Sci. Hortic.-Amsterdam 184: 171-178, 2015.

Godo T., Fujiwara K., Guan K., Miyoshi K.: Effects of wavelength of LED-light on in vitro asymbiotic germination and seedling growth of Bletilla ochracea Schltr. (Orchidaceae). - Plant Biotechnol. 28: 397-400, 2011.

Haliapas S., Yupsanis T.A., Syros T.D. et al.: Petunia $\times$ hybrida during transition to flowering as affected by light intensity and quality treatments. - Acta Physiol. Plant. 30: 807-815, 2008.

Heath R.L., Packer L.: Photoperoxidation in isolated chloroplasts. I. Kinetics and stoichiometry of fatty acid peroxidation. Arch. Biochem. Biophys. 125: 180-198, 1968.

Hemming S., Mohammadkhani V., Dueck T.: Diffuse greenhouse covering materials - material technology, measurements and evaluation of optical properties. - Acta Hortic. 797: 469-475, 2008.

Hernández R., Kubota C.: Tomato seedling growth and morphological responses to supplemental LED lighting red:blue rations under varied daily solar light integrals. - Acta Hortic. 956: 187-194, 2012.

Hernández R., Kubota C.: Physiological responses of cucumber seedlings under different blue and red photon flux ratios using LEDs. - Environ. Exp. Bot. 12: 66-74, 2016.

Hogewoning S.W., Trouwborst G., Maljaars H. et al:: Blue light dose - responses of leaf photosynthesis, morphology, and chemical composition of Cucumis sativus grown under different combinations of red and blue light. - J. Exp. Bot. 61: 3107-3117, 2010.

Kami C., Lorrain S., Hornitschek P., Fankhauser C.: Light regulated plant growth and development. - In: Timmermans M.C.P. (ed.): Plant Development. Current Topics in Developmental Biology. Vol. 91. Pp. 29-66. Elsevier, San Diego 2010.

Kim K., Kook H., Jang Y. et al.: The effect of blue-emitting-light diodes on antioxidant properties and resistance to Botrytis cinerea in tomato. - J. Plant Pathol. Microb. 4: 9, 2013.

Kim S.J., Hahn E.J., Heo J.W., Paek K.Y.: Effects of LEDs on net photosynthetic rate, growth and leaf stomata of chrysanthemum plantlets in vitro. - Sci. Hortic.-Amsterdam 
101: 143-151, 2004.

Kim T.H., Kim B.H., von Arnim A.G.: Repressors of photomorphogenesis. - Int. Rev. Cytol. 220: 185-223, 2002.

Kirchhoff H.: Chloroplast ultrastructure in plants. - New Phytol. 223: 565-574, 2019.

Kurepin L.V., Walton L.J., Reid D.M.: Interaction of red to far red light ratio and ethylene in regulating stem elongation of Helianthus annuus. - Plant Growth Regul. 51: 53-61, 2007.

Kurutas E.B.: The importance of antioxidants which play the role in cellular response against oxidative/nitrosative stress: current state. - Nutr. J. 15: 71, 2016.

Lall N., Nikolova R.V., Bosa A.J.N.: Changes in activities of superoxide dismutase, peroxidase and catalase from leaves of Impatiens flanaganiae in response to light intensity. $-\mathrm{S}$. Afr. J. Bot. 65: 255-259, 1999.

Landi M., Zivcak M., Sytar O. et al.: Plasticity of photosynthetic processes and the accumulation of secondary metabolites in plants in response to monochromatic light environments: A review. - BBA-Bioenergetics 1861: 148131, 2020.

Li H., Tang C., Xu Z. et al.: Effects of different light sources on the growth of non-heading Chinese cabbage (Brassica campestris L.). - J. Agr. Sci. 4: 262-273, 2012.

Li Q., Kubota C.: Effects of supplemental light quality on growth and phytochemicals of baby leaf lettuce. - Environ. Exp. Bot. 67: 59-64, 2009.

Liu H., Fu Y., Yu J., Liu H.: Accumulation and primary metabolism of nitrate in lettuce (Lactuca sativa L. var. Youmaicai) grown under three different light sources. - Commun. Soil Sci. Plan. 47: 1994-2002, 2016.

Liu Q., Zheng L., He F. et al.: Transcriptional and physiological analyses identify a regulatory role for hydrogen peroxide in the lignin biosynthesis of copper-stressed rice roots. - Plant Soil 387: 323-336, 2015.

Ma X., Zhang X., Yang L. et al:: Hydrogen peroxide plays an important role in PERK4-mediated abscisic acid-regulated root growth in Arabidopsis. - J. Funct. Plant Biol. 46: 165$174,2019$.

Mani S., Van De Cotte B., Van Montagu M., Verbruggen N.: Altered levels of proline dehydrogenase cause hypersensitivity to proline and its analogs in Arabidopsis. - Plant Physiol. 128: 73-83, 2002.

Manivannan A., Soundararajan P., Halimah N. et al.: Blue LED light enhances growth, phytochemical contents, and antioxidant enzyme activities of Rehmannia glutinosa cultured in vitro. - Hortic. Environ. Biote. 56: 105-113, 2015.

Mitchell C.A., Both A., Bourget C.M. et al.: LEDs: the future of greenhouse lighting. - Chron. Hortic. 55: 6-12, 2012.

Nanya K., Ishigami Y., Hikosaka S., Goto E.: Effects of blue and red light on stem elongation and flowering of tomato seedlings. - Acta Hortic. 956: 261-266, 2012.

Pinho P.: Usage and control of solid-state lighting for plant growth. Dissertation. Pp. 60. Helsinki University of Technology, Espoo 2008.

Procházková D., Sairam R.K., Srivastava G.C., Singh D.V.: Oxidative stress and antioxidant activity as the basis of senescence in maize leaves. - Plant Sci. 161: 765-771, 2001.

Rehman M., Gang D., Liu Q. et al.: Ramie, a multipurpose crop: potential applications, constraints and improvement strategies. - Ind. Crop Prod. 137: 300-307, 2019.

Sager J.C., McFarlane J.C.: Radiation. - In: Langhans R.W., Tibbitts T.W. (ed.): Plant Growth Chamber Handbook. North Central Region Research Publication No. 340. Iowa Agriculture and Home Economics Experiment Station Special Report No. 99. Pp. 29. Iowa State University Press, Ames 1997.

Sakharov I.Y., Aridilla G.B.: Variation of peroxidase activity in cacao beans during their ripening, fermentation and drying. Food Chem. 65: 51-54, 1999.

Saleem M.H., Rehman M., Zahid M. et al.: Morphological changes and antioxidative capacity of jute (Corchorus capsularis, Malvaceae) under different color light-emitting diodes. - Braz. J. Bot. 42: 581-590, 2019.

Saud S., Chen Y., Fahad S. et al.: Silicate application increases the photosynthesis and its associated metabolic activities in Kentucky bluegrass under drought stress and post-drought recovery. - Environ. Sci. Pollut. R. 23: 17647-17655, 2016.

Saud S., Chen Y., Long B. et al.: The different impact on the growth of cool season turf grass under the various conditions on salinity and drought stress. - Int. J. Agric. Sci. Res. 3: 7784, 2017a.

Saud S., Fahad S., Yajun C. et al.: Effects of nitrogen supply on water stress and recovery mechanisms in Kentucky bluegrass plants. - Front. Plant Sci. 8: 983, 2017 b.

Saud S., Li X., Chen Y. et al.: Silicon application increases drought tolerance of Kentucky bluegrass by improving plant water relations and morphophysiological functions. - Sci. World J. 2014: 368694, 2014.

Sharma P., Jha A.B., Dubey R.S., Pessarakli M.: Reactive oxygen species, oxidative damage, and antioxidative defense mechanism in plants under stressful conditions. - J. Bot. 2012: 217037, 2012.

Shimizu H., Saito Y., Nakashima H. et al.: Light environment optimization for lettuce growth in plant factory. - IFAC Proc. Vol. 44: 605-609, 2011.

Simlat M., Ślęzak P., Mos M. et al.: The effect of light quality on seed germination, seedling growth and selected biochemical properties of Stevia rebaudiana Bertoni. - Sci. Hortic.Amsterdam 211: 295-304, 2016.

Singh D., Basu C., Meinhardt-Wollweber M., Roth B.: LEDs for energy efficient greenhouse lighting. - Renew. Sust. Energ. Rev. 49: 139-147, 2015.

Szabados L., Savouré A.: Proline: a multifunctional amino acid. Trends Plant Sci. 15: 89-97, 2010.

Taiz L., Zeiger E.: Plant Physiology. $3^{\text {rd }}$ Edition. Pp. 675. Sinauer Associates, Sunderland 2002.

Taylor A.R., Assmann S.M.: Apparent absence of a redox requirement for blue light activation of pump current in broad bean guard cells. - Plant Physiol. 125: 329-338, 2001.

Trouwborst G., Oosterkamp J., Hogewoning S.W. et al.: The responses of light interception, photosynthesis and fruit yield of cucumber to LED-lighting within the canopy. - Physiol. Plantarum 138: 289-300, 2010.

Turan V.: Confident performance of chitosan and pistachio shell biochar on reducing Ni bioavailability in soil and plant plus improved the soil enzymatic activities, antioxidant defense system and nutritional quality of lettuce. - Ecotox. Environ. Safe. 183: 109594, 2019.

Turan V.: Potential of pistachio shell biochar and dicalcium phosphate combination to reduce $\mathrm{Pb}$ speciation in spinach, improved soil enzymatic activities, plant nutritional quality, and antioxidant defense system. - Chemosphere 245: 125611, 2020.

Vänninen I., Pinto-Zevallos D.M., Nissinen A.I. et al.: In the light of new greenhouse technologies: 1. Plant-mediated effects of artificial lighting on arthropods and tritrophic interactions. Ann. Appl. Biol. 157: 393-414, 2010.

Wang Y., Tong Y., Chu H. et al.: Effects of different light qualities on seedling growth and chlorophyll fluorescence parameters of Dendrobium officinale. - Biologia 72: 735-744, 2017.

Wu M.C., Hou C.Y., Jiang C.M. et al.: A novel approach of LED light radiation improves the antioxidant activity of pea seedling. - Food Chem. 101: 1753-1758, 2007. 
Yanagi T., Okamoto K., Takita S.: Effect of blue and red light intensity on photosynthetic rate of strawberry leaves. - Acta Hortic. 440: 371-376, 1996.
Yeh N., Chung J.-P.: High-brightness LEDs-energy efficient lighting sources and their potential in indoor plant cultivation. - Renew. Sust. Energ. Rev. 13: 2175-2180, 2009.

(C) The authors. This is an open access article distributed under the terms of the Creative Commons BY-NC-ND Licence. 